Provided for non-commercial research and education use. Not for reproduction, distribution or commercial use.

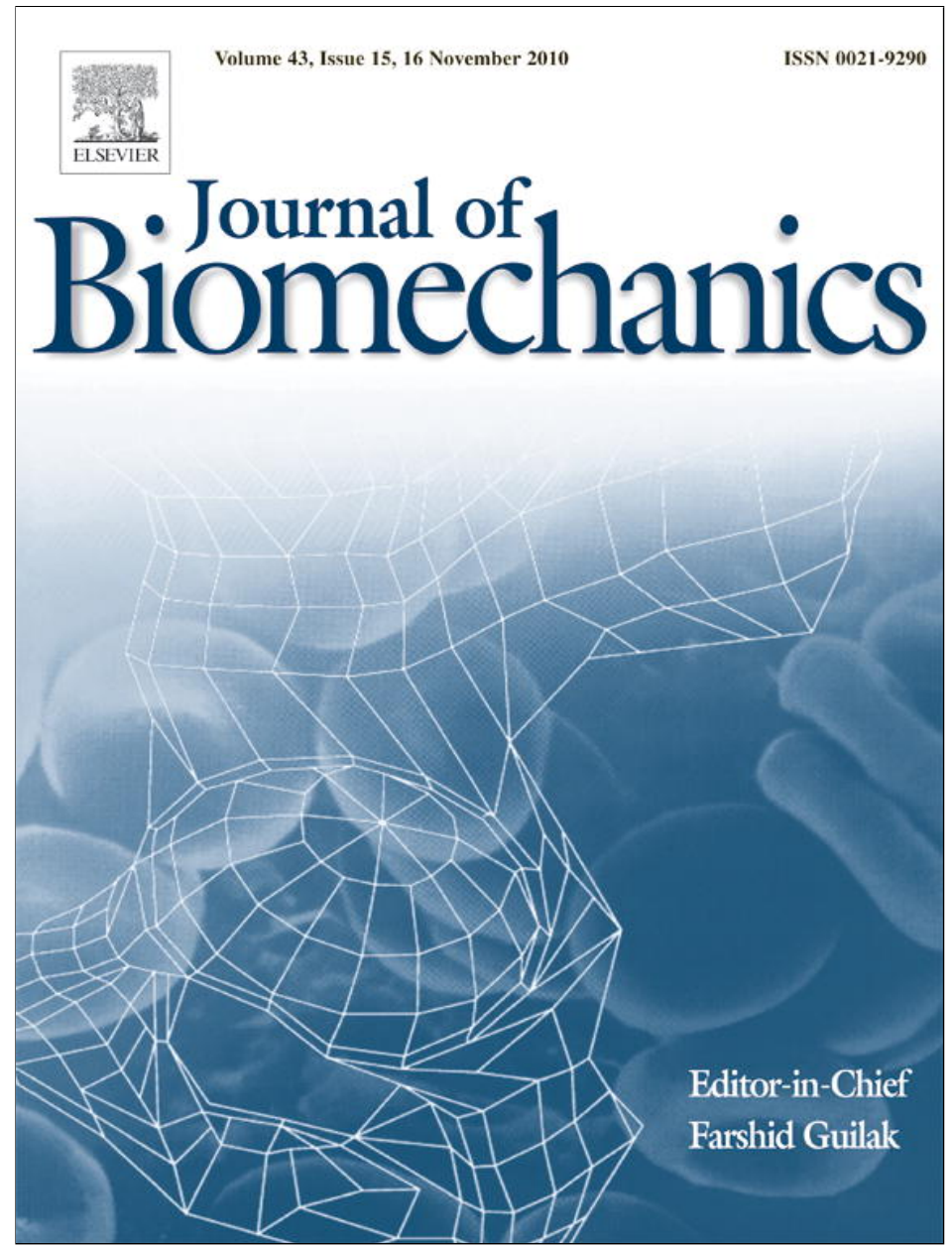

This article appeared in a journal published by Elsevier. The attached copy is furnished to the author for internal non-commercial research and education use, including for instruction at the authors institution and sharing with colleagues.

Other uses, including reproduction and distribution, or selling or licensing copies, or posting to personal, institutional or third party websites are prohibited.

In most cases authors are permitted to post their version of the article (e.g. in Word or Tex form) to their personal website or institutional repository. Authors requiring further information regarding Elsevier's archiving and manuscript policies are encouraged to visit:

http://www.elsevier.com/copyright 


\title{
The epigenetic mechanism of mechanically induced osteogenic differentiation
}

\author{
Emily J. Arnsdorf ${ }^{\mathrm{a}, \mathrm{b}}$, Padmaja Tummala ${ }^{\mathrm{a}}$, Alesha B. Castillo ${ }^{\mathrm{a}, \mathrm{c}}$, Fan Zhang ${ }^{\mathrm{d}}$, Christopher R. Jacobs ${ }^{\mathrm{a}, \mathrm{b}, \mathrm{c}, \mathrm{e}, *}$ \\ a Bone and Joint Rehabilitation RED Center, VA Palo Alto Medical Center, Palo Alto, CA, United States \\ ${ }^{\mathrm{b}}$ Stanford University, Department of Bioengineering, Stanford, CA, United States \\ ' Stanford University, Department of Mechanical Engineering, Stanford, CA, United States \\ d Stanford University, Departments of Microbiology and Immunology, Stanford, CA, United States \\ e Columbia University, Department of Biomedical Engineering, NY, NY, United States
}

\section{A R T I C L E I N F O}

Article history:

Accepted 21 July 2010

\section{Keywords:}

Mesenchymal stem cell

Osteogenic differentiation

Mechanotransduction

Epigenetic

\begin{abstract}
A B S T R A C T
Epigenetic regulation of gene expression occurs due to alterations in chromatin proteins that do not change DNA sequence, but alter the chromatin architecture and the accessibility of genes, resulting in changes to gene expression that are preserved during cell division. Through this process genes are switched on or off in a more durable fashion than other transient mechanisms of gene regulation, such as transcription factors. Thus, epigenetics is central to cellular differentiation and stem cell linage commitment. One such mechanism is DNA methylation, which is associated with gene silencing and is involved in a cell's progression towards a specific fate. Mechanical signals are a crucial regulator of stem cell behavior and important in tissue differentiation; however, there has been no demonstration of a mechanism whereby mechanics can affect gene regulation at the epigenetic level. In this study, we identified candidate DNA methylation sites in the promoter regions of three osteogenic genes from bone marrow derived mesenchymal stem cells (MSCs). We demonstrate that mechanical stimulation alters their epigenetic state by reducing DNA methylation and show an associated increase in expression. We contrast these results with biochemically induced differentiation and distinguish expression changes associated with durable epigenetic regulation from those likely to be due to transient changes in regulation. This is an important advance in stem cell mechanobiology as it is the first demonstration of a mechanism by which the mechanical micro-environment is able to induce epigenetic changes that control osteogenic cell fate, and that can be passed to daughter cells. This is a first step to understanding that will be vital to successful bone tissue engineering and regenerative medicine, where continued expression of a desired long-term phenotype is crucial.
\end{abstract}

(c) 2010 Elsevier Ltd. All rights reserved.

\section{Introduction}

In this paper, we address the potential for the micromechanical environment of tissue to alter the epigenetic state of stem cells. Epigenetics refers to molecular alterations of DNA that change gene expression without changing DNA sequence, typically through changes in chromatin proteins that alter DNA accessibility for transcription allowing some genes to be activated and others to be silenced. Furthermore, the epigenetic state of a cell is heritable in the sense that it is preserved during cell division. Therefore, a cell's gene expression pattern, or phenotype, is a result of not only the transient signals it might receive causing

\footnotetext{
* Corresponding author at: 351 Engineering Terrace, Department of Biomedical Engineering, Columbia University, NY 10027, NY, United States.

Tel.: +12128510271.

E-mail address: Christopher.jacobs@columbia.edu (C.R. Jacobs).
}

up or down regulation of particular genes, but also the epigenetic inheritance system that controls which genes are available for transcription. Thus, epigenetic changes to DNA allow for a cellular memory and are central to the process of differentiation for cells and tissues (Bird, 2002; El-Osta and Wolffe, 2000; Li and Zhao, 2008; Nagase and Ghosh, 2008; Reik and Dean, 2001; Zhang et al., 2007).

The remedial strategies for repair, replacement or augmentation of damaged or diseased bone tissue through regenerative medicine applications shows great promise for restoring function, relieving pain, and improving the quality of life (Goldstein, 2006). However, understanding the mechanism whereby extracellular factors regulate stem cell biology and lineage commitment is critical for successful development of novel strategies in regenerative medicine (Estes et al., 2004; McBeath et al., 2004). For example, to ensure engineered tissues continue to express desired characteristics, it is crucial to distinguish transient changes in phenotype from true cellular differentiation. 
In terms of bone tissue engineering, a potent extracellular factor controlling cell activity is the mechanical micro-environment. Previous reports show that skeletal loading is a key regulator of bone metabolism controlling bone turnover, growth, and mineralization (Dehority et al., 1999; Lafage-Proust et al., 1998; Triplett et al., 2007; Wronski et al., 1987). In vitro studies have shown that, at a cellular level, mechanics play a key role in the regulation of osteogenic activity in both osteoblasts and osteocytes (Batra et al., 2005; Kim et al., 2006; Malone et al., 2007; Saunders et al., 2001; Saunders et al., 2003; You et al., 2001; You et al., 2000). Additionally, recent studies demonstrate that exposure to loading-induced dynamic fluid flow results in the transcription of osteoblast-phenotype markers in MSCs, indicating that the mechanical environment plays an important role in guiding stem cell differentiation (Friedl et al., 2007; Kreke et al., 2005; Li et al., 2004).

Cellular differentiation is commonly assessed by particular protein expression patterns resulting from specific patterns of gene expression; however, epigenetic modifications modulate transcription factor accessibility and thus, alter gene expression in an inherited fashion. The main epigenetic mechanisms of gene regulation are DNA methylation and histone modification (Nagase and Ghosh, 2008). DNA methylation is a chromatin alteration that consists of the addition of a methyl group to the $5^{\prime}$ position of cytosine in a CpG dinucleotide (CpG indicates cytosine-phosphate-guanine to distinguish it from CG base pairing between complementary DNA strands) in gene regulatory regions and largely contributes to gene silencing (Noer et al., 2006). Specifically, DNA methylation either directly blocks transcription factor binding or enhances binding of proteins that induce a more transcription-resistant condensed chromatin (Antequera, 2003; Ballestar and Wolffe, 2001; El-Osta and Wolffe, 2000; Fuks et al., 2003; Wolffe and Matzke, 1999). Given that DNA methylation regulates gene expression in a durable and heritable manner, it is a more relevant method of evaluating differentiation than protein expression alone (Friedl et al., 2007; Lachner, 2002; Lachner and Jenuwein, 2002). However, although epigenetic modifications are key in embryonic stem cell biology and development, relatively little is understood about how DNA methylation patterns change during differentiation in adult MSCs (Kang et al., 2007; Li and Zhao, 2008; Noer et al., 2006). Furthermore, the potential of the micro-mechanical environment to regulate DNA methylation has never been examined, and is fundamental to understanding stem cell mechanobiology.

In this study, we examined whether oscillatory fluid flow, an exogenous physical signal that is regulated by bone loading and occurs in the microenvironment of bone cells, has the potential to induce alterations in DNA methylation and gene expression of the late stage osteogenic genes Collagen 1, Osteocalcin, and Osteopontin in murine derived bone marrow progenitor cells. We used combined bisulfite restriction enzyme analysis (COBRA) to determine if mechanical stimuli regulate the induction of gene expression via modifications to the methylated state of gene regulatory regions and contrasted the findings with biochemically induced differentiation. We demonstrate, for the first time, that mechanical stimulation can cause alterations to the epigenetic state of chromatin, guiding osteogenic differentiation by hypomethylation of the Osteopontin promoter and an associated increase in Osteopontin mRNA levels. We also sought to determine the extent to which mechanically and biochemically induced differentiation shared common molecular mechanisms. Therefore we examined biochemically induced differentiation for comparison. Our results suggest a mechanism whereby mechanics regulates stem cell fate commitment, which may prove vital to developing optimal strategies for durable functional tissue engineering.

\section{Methods}

\subsection{Cell isolation, passage number, media}

Bone marrow progenitor cells were isolated from the tibiae of six-week-old C57/Bl 6 mice. Briefly, hindlimbs were rinsed in ethanol and placed in PBS on ice. The tibiae were isolated, washed with $70 \%$ ethanol and using a $3 \mathrm{~mL}$ syringe with a $50 \mathrm{G}$ needle, the bone marrow cavity was flushed with alpha modified minimal essential medium (Invitrogen) containing 10\% fetal bovine serum (Hyclone), $1 \%$ penicillin and streptomycin (PS) (Invitrogen). Cells were maintained at $37^{\circ} \mathrm{C}$ and $5 \% \mathrm{CO}_{2}$ in a humidified incubator. Media was changed everyday for 5 days and remaining adherent cells were used in experiments. All experiments were conducted with cells in their first passage.

\subsection{Mechanically induced differentiation}

Cells were subcultured on fibronectin-coated glass slides $(76 \mathrm{~mm} \times 35 \mathrm{~mm} \times 1$ $\mathrm{mm}$ ). Once cells reached $80-90 \%$ confluence, the glass slides were loaded into parallel plate flow chambers and experimental cells were exposed to 3 hours of oscillatory fluid flow. A previously described fluid flow device was used to deliver fluid flow (Jacobs et al., 1998). In brief, flow was driven by a Hamilton glass syringe in series with rigid walled tubing and a parallel plate flow chamber. The syringe was mounted in and driven by a mechanical loading device. The flow rate was monitored with an ultrasonic flow meter (Transonic Systems Inc.) and was selected to yield a peak wall shear stress of $1.0 \mathrm{~Pa}\left(10 \mathrm{dyn} / \mathrm{cm}^{2}\right)$. The dynamic flow profile was sinusoidal at a frequency of $1 \mathrm{~Hz}$. Following the cessation of flow, cells were incubated in fresh growth media and lysed $24 \mathrm{~h}$ later for RNA or DNA isolation. Control cells were cultured on fibronectin glass slides, loaded into parallel plate flow chambers for $3 \mathrm{~h}$ without fluid flow, and then cultured in fresh growth media for $24 \mathrm{~h}$.

\subsection{Biochemically induced differentiation}

After an initial 5 days in culture, progenitor cells were subcultured on fibronectin-coated glass slides in either (1) growth media or (2) osteo-inductive media consisting of growth media supplemented with $10 \mathrm{mM} \beta$-glycerolphosphate (Sigma), and $250 \mu \mathrm{M}$ ascorbic-acid-2-phosphate (Sigma) and $1 \mu \mathrm{M}$ dexamethasone (MP Biomedical). The cells cultured in growth media were lysed once they reached $80-90 \%$ confluence and served as control cells (labeled as Early Culture Progenitor Cells). Cells in osteo-inductive media were maintained at $37^{\circ} \mathrm{C}$ and $5 \% \mathrm{CO}_{2}$ in a humidified incubator and media was changed every two days for 14 days at which point they were lysed for DNA or RNA isolation.

\subsection{RNA isolation and real-time $R T-P C R$}

Cells were lysed and total RNA was isolated using Tri-Reagent (Sigma). The $260 / 280$ absorbance ratio was measured using an ND-1000 Spectrometer (NanoDrop) for verification of the purity and concentration of the RNA. Reverse transcription was completed using GeneAMP RNA PCR Core kit (Applied Biosystems) with $1.5 \mu \mathrm{g}$ of RNA. Analysis by quantitative real-time RT-PCR (Applied Biosystems) was conducted using Taqman PCR Master Mix and primers and probes for 18S, Osteopontin and Collagen I (Applied Biosystems), or by using SYBER green PCR master mix with primers and probes developed by Operon technologies for Osteocalcin. The primer sequence for Osteocalcin was: Forward 5'-GAG TCT GAC AAA GCC TTC A-3'; Reverse 5'-AGC CAT ACT GGT CTG ATA G-3'.

\subsection{DNA isolation}

Cells were trypsinized, pelleted, and DNA was extracted by using the DNeasy Tissue Kit (Qiagen). DNA was eluted in $200 \mu$ of AE buffer, and the concentration was measured, using an ND-1000 Spectrometer (NanoDrop).

\subsection{Bisulfite treatment of DNA and primer design}

Initially, $1.5 \mu \mathrm{g}$ of DNA was mixed with $0.5 \mu \mathrm{l}$ of EcoRI (20 units $/ \mu \mathrm{l}$; NEB), $4.5 \mu \mathrm{l}$ of EcoRI buffer (NEB), and DNase free $\mathrm{H}_{2} \mathrm{O}$ to reach a total volume of $45 \mu \mathrm{l}$. Enzyme digestion was carried out at $37^{\circ} \mathrm{C}$ for $4 \mathrm{~h}$. To denature the DNA, samples were heated at $70{ }^{\circ} \mathrm{C}$ for $25 \mathrm{~min}$ followed by $97^{\circ} \mathrm{C}$ for $5 \mathrm{~min}$. After cooling to room temperature, bisulfite treatment was conducted using the EZ DNA Methylation kit (ZYMO Research). Briefly, $5 \mu \mathrm{l}$ of M-dilution buffer was added, mixed, and then incubated at $42{ }^{\circ} \mathrm{C}$ for $30 \mathrm{~min}$. After incubation, $100 \mu \mathrm{l}$ of CT conversion reagent was added, and DNA samples were incubated at $55{ }^{\circ} \mathrm{C}$ for $15 \mathrm{~h}$. The resulting bisulfite-treated DNA was purified. The DNA was eluted in $20 \mu \mathrm{l}$ of M-elution buffer, and $4 \mu$ l of this was used in each bisulfite-specific PCR amplification. Genespecific primers were designed to be bisulfite-specific and complementary to one of the converted DNA strands with no CpG dinucleotides in the original sequences. 
Primer sequences used were: Collagen 1 Forward: 5'-ATTG GGAG TAGG GAAA GGGA GT-3'; Collagen 1 Reverse: 5'-ATAA CTTA TAAC CCAA AATC TACC CCC-3'; Osteopontin Forward: 5'-TGTG GAGT TTTA GAGA TATT AGAT AGTG GG-3'; Osteopontin Reverse: 5'-AACA CACT CTTA ACAC CACT AAAT CACC-3'; Osteocalcin Forward: 5'-GGGT TTGA TTTA TTGA GTAT ATGA TTTT TAAT TAGT-3'; Osteocalcin Reverse: 5'-TACC ATCC CAAA ACAA ATTA TAAA ACCT-3'.

\subsection{Bisulfite-specific PCR, restriction enzyme digestion, and gel electrophoresis}

PCR amplifications were carried out with Takara LA Taq Hot Start PCR Kit (Takara Bio Enc, Otsu, Shiga, Japan) with the following regimen: $35 \times\left(95^{\circ} \mathrm{C}\right.$ for $1 \mathrm{~min}, 94^{\circ} \mathrm{C}$ for $30 \mathrm{~s}, 58^{\circ} \mathrm{C}$ for $30 \mathrm{~s}, 72{ }^{\circ} \mathrm{C}$ for $\left.50 \mathrm{~s}\right)$ and $72{ }^{\circ} \mathrm{C}$ for $10 \mathrm{~min} .17 \mu \mathrm{lPCR}$ product was digested with $2 \mu \mathrm{l}$ of HpyCH4IV (10 units/ $\mu \mathrm{l}$ ) and $4 \mu \mathrm{l}$ of NEBuffer 1 at $37{ }^{\circ} \mathrm{C}$ for $2 \mathrm{~h}$. The digested PCR products were separated by agarose gel electrophoresis. Digital gel images were acquired by using a Fuji Imager and were analyzed by Fuji Film Multigage software (version 2.3) from Fujifilm Global. The values of the total intensity minus the background of all of the bands were exported to Microsoft Excel. The percentage of methylation in a given sample was calculated as the ratio of the intensity of cleaved PCR products to that of the total PCR products.

\subsection{Data analysis}

Data are expressed as mean \pm SE. Osteocalcin, Osteopontin, and Collagen I gene expression levels were normalized against 18S rRNA assayed in the same sample tube. ANOVA statistical analysis was conducted using Statview software. A post-hoc paired t-test was used to compare control and mechanically stimulated cells, or to compare early progenitors with biochemically differentiated cells. A $p<0.05$ was considered significant.

\section{Results}

\subsection{Identification of specific DNA methylation sites in promoter} regions of Collagen I, Osteocalcin, and Osteopontin

Using bisulfite-specific primers for PCR followed by restriction enzyme digestions and gel electrophoresis, we determined candidate point locations of methylation in each of the genes investigated (Fig. 1).

The amplicon for Collagen 1 was 353 bp long and was located $2000 \mathrm{bp}$ upstream of the site of transcription, containing one potential site for methylation. Digestion with HypCh4IV, which recognizes the sequence, 5'-ACGT-3', followed by electrophoresis demonstrated that a large subpopulation of bone marrow progenitor cells have this CPG site methylated (Fig. 1B). $71.1 \pm 9.5 \%$ of early progenitor cells had this target methylated and upon biochemically induced osteogenic differentiation this CpG site was only $62.7 \pm 5.6 \%$ methylated. Furthermore, progenitor cells that had been exposed to oscillatory fluid flow had $80.8 \pm 2.0 \%$ methylation, while controls had $79.5 \pm 2.3 \%$ methylation.

For Ostecalcin, the PCR product was $467 \mathrm{bp}$ in length and had one potential target for methylation. Enzyme digestion with HypCH4IV and electrophoresis revealed that a small population within bone marrow has this site methylated (Fig. 1C). Osteocalcin promoter methylation was the same under all conditions with $12.9 \pm 1.3 \%$ methylation in early progenitor cells, $14.1 \pm 2.7 \%$ methylation in differentiated cells, $12.0 \pm 0.3 \%$ in cells exposed to flow, and $12.7 \pm 3.0 \%$ methylation in control cells.

Finally, the 227 bp long PCR amplicon for Osteopontin also had one potential site for methylation and, similar to Osteocalcin, a small subpopulation had this site methylated (Fig. 1D). Of about $10.5 \pm 1.1 \%$ of early progenitor cells had this site methylated, while $5.9 \pm 0.8 \%$ of osteogenically induced cells had the targeted site methylated. Additionally, $9.6 \pm 1.3 \%$ of cells were methylated after an exposure to fluid flow, while $14.7 \pm 1.5 \%$ of controls had the target $\mathrm{CpG}$ site methylated.

\subsection{DNA methylation and gene expression are not directly correlated with biochemically induced osteogenic differentiation}

With biochemically induced differentiation, gene expression levels and percent DNA methylation do not correlate in all genes examined (Fig. 2). Collagen I was not significantly upregulated upon osteogenic differentiation; however, both osteopontin and osteocalcin mRNA expression were increased 32.5-fold $(p<0.01)$ and 1770 -fold $(p<0.01)$, respectively. Methylation of the Osteopontin promoter was significantly altered with a $43.9 \%$ decrease with biochemically induced osteogenic differentiation $(p<0.01)$. However, the methylation of the Collagen 1 and Osteocalcin promoter was not altered by biochemically induced differentiation.

\subsection{Mechanical stimulation upregulates Osteopontin gene expression and promoter DNA demethylation}

Exposing bone marrow mesenchymal progenitor cells to $3 \mathrm{~h}$ of oscillatory fluid flow induced alterations in both gene expression and DNA methylation within $24 \mathrm{~h}$ (Fig. 3). Osteopontin gene expression was increased 2.3-fold $(p<0.01)$ and additionally, there was a $35 \%$ decrease in DNA methylation in the promoter region of Osteopontin with exposure to flow $(p<0.05)$. Collagen I and Osteocalcin were not upregulated with flow, and there was no significant difference in methylation with flow.

\section{Discussion}

Stem cell mechanobiology is a complex interplay that integrates the cutting edge of the fields of mechanics and biology. Increasingly, breakthroughs are occurring from the application of biomechanical techniques at the cell and molecular levels. These new insights are important because mechanics is a critical regulator of many biological systems. In the context of tissue engineering, it is vital to understand the mechanisms whereby the cell's mechanical environment regulates phenotypic expression so that engineered tissues can be designed to achieve and maintain desired characteristics over the long-term. The major finding of this paper is the first direct demonstration of a mechanism, whereby mechanical signals alter the epigenetic state of stem cells and thereby affect cell fate.

We first examined the effect of mechanical stimulation in the form of dynamic fluid flow on bone marrow derived MSCs. We found an increase in Osteopontin gene expression similar to that reported in human MSCs (Li et al., 2004). We also found a CpG DNA methylation site in the promoter region of the Osteopontin gene that was demethylated with exposure to flow. Thus, the change in Osteopontin expression with mechanical stimulation is likely the result of a heritable epigenetic alteration to chromatin rather than a transient change in expression. We then contrasted these results with biochemically induced differentiation, which also resulted in the upregulation of Osteopontin and hypomethylation of its promoter. However, biochemical stimulation also resulted in a dramatic upregulation of Osteocalcin. But, this increase was not associated with alterations in promoter methylation. This may be reflective of a more transient change in expression mediated by transcription factors or post-translational modifications to histone proteins rather than a durable change in progenitor commitment. This is illustrative of how understanding the mechanism behind differentiation rather than phenotypic changes alone can distinguish durable heritable effects from transient ones. We did not observe 
A

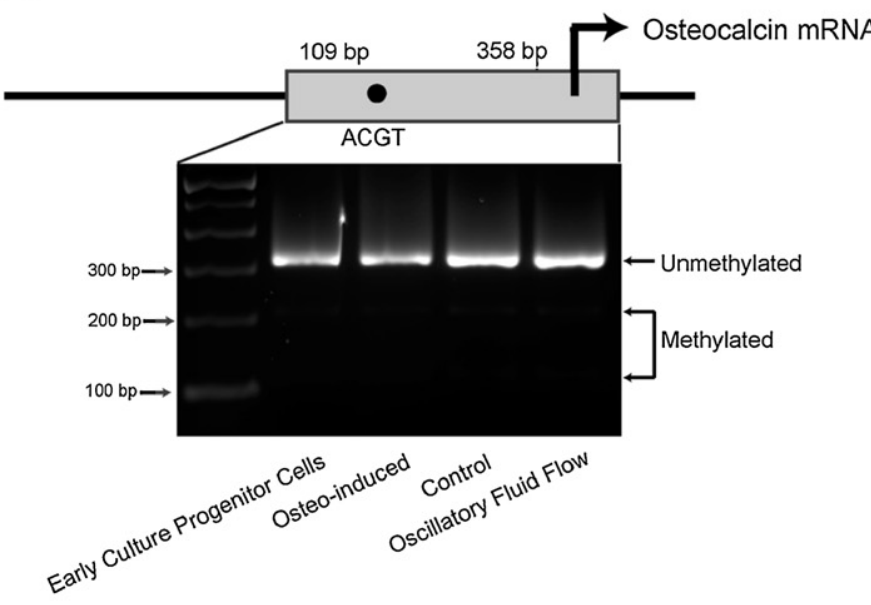

B

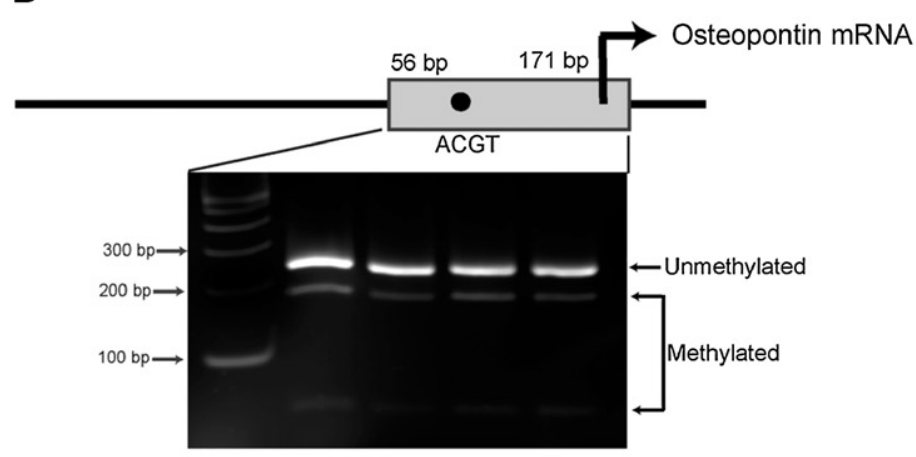

C

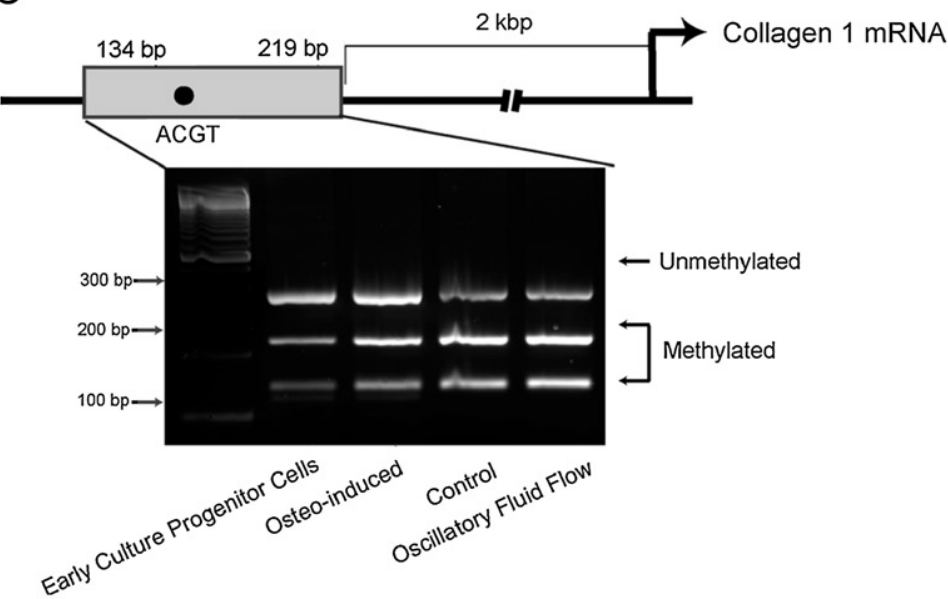

Fig. 1. Schematic depictions of the location and designated lengths of amplicon segments and representative electrophoresis gels for MSCs exposed to biochemical and biomechanical stimulation. (A) The Osteocalcin amplicon was $467 \mathrm{bp}$ in length and had one potential target for methylation. Methylation was not affected with biochemical or biomechanical stimulation. (B) The PCR product for Osteopontin was 227 bp long and had one potential target for methylation. MSCs did have this site methylated and its methylation state altered by both biochemical and biomechanical stimulation. (A) For Collagen 1, the PCR product was a 353 bp amplicon located 2 kbp upstream of the site of transcription. Our analysis indicates that this target was also methylated, but was not altered with either stimulation.
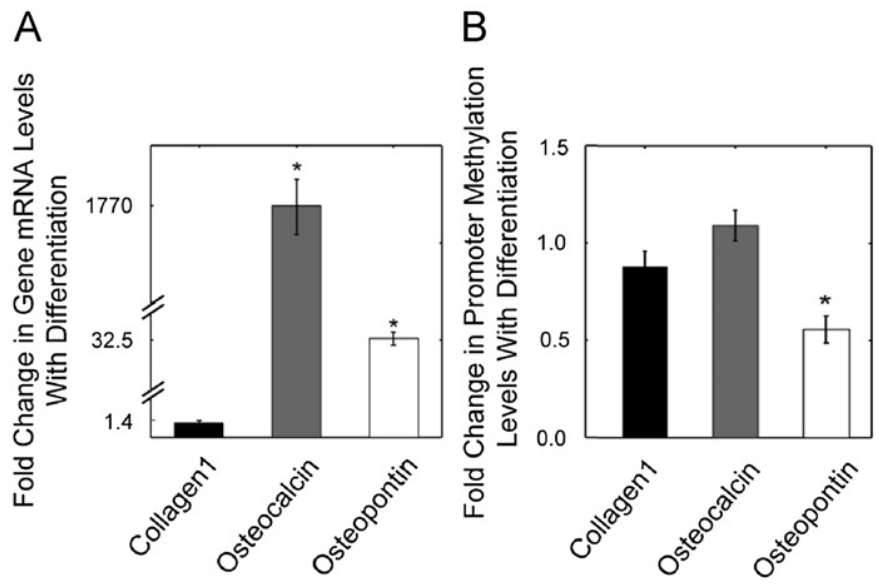

Fig. 2. Quantification of gene expression and methylation in response to biochemical stimulation. (A) The gene expression levels of MSCs cultured in osteo-inductive media for 2 weeks varied in only late stage osteogenic genes. Osteocalcin and Osteopontin were upregulated 1770.9-fold $(p<0.01)$ and 32.5fold $(p<0.01)$, respectively. (B) Collagen 1 promoter methylation was not significantly altered by exposure to differentiation media. Furthermore, the methylation of osteopontin decreased by $43.9 \%$ after biochemically induced osteogenic differentiation $(p<0.01)$. Osteocalcin promoter methylation was not altered. [Error bars: SEM $(n \geq 4)$ ].
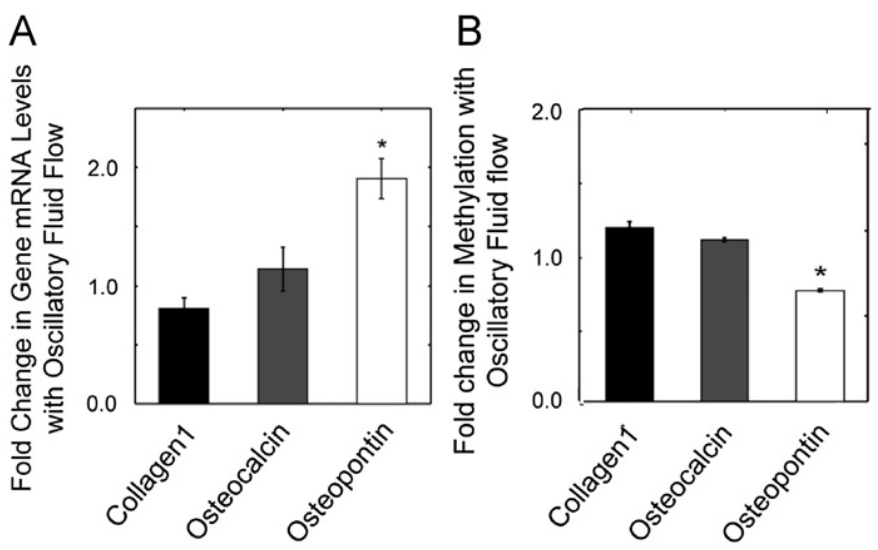

Fig. 3. Mechanically induced alterations in gene expression (A) and promoter methylation (B). Neither gene expression nor promoter methylation of Collagen 1 and Osteocalcin was altered by oscillatory fluid flow. Osteopontin gene expression increased by 2.3 -fold $(p<0.01)$, corresponding to a promoter methylation decrease of 1.5 -fold $(p<0.05)$. [Error bars: SEM $(n \geq 8)$ ].

a change in Collagen I expression or methylation of its promoter for either stimulus, consistent with prior observation ( $\mathrm{Li}$ et al., 2004). 
An important limitation of this study is that we only identified and examined a single methylation site in each gene regulatory region. Typically, many such sites exist, and to be certain of the role of DNA methylation in mechanically regulated gene expression a more systematic high-throughput approach is required. Furthermore, other epigenetic mechanisms may be involved such as modification of histone proteins that can also induce chromatin condensation making DNA less accessible for transcription. These caveats aside, our results remain an important first step in showing that the mechanical environment is a potentially critical epigenetic regulating factor.

Our findings may also be influenced by our source of MSCs. Bone marrow derived MSCs may have already undergone initial alterations in methylation of some genes, priming themselves for osteogenic cell fate commitment. For example, with biochemically induced differentiation, there was a significant increase in Osteocalcin gene expression, but there was no observed change in methylation. This may be explained if the heritable epigenetic modification had already been pre-programmed in the cells. A similar conclusion has been described by Noer and colleagues suggesting that adipose derived MSCs are epigenetically preprogrammed for adipogenic differentiation (Noer et al., 2006). However, a comprehensive examination of DNA methylation as a function of stem cell source would more definitively address the extent to which epigenetic pre-programming from the source tissue limits potential tissues that could be generated.

Mechanical stimulation did not have an effect on Osteocalcin or Collagen I expression or methylation. However, alterations in expression or methylation of these two genes may be a late stage indication of osteogenic differentiation that is not induced by only $3 \mathrm{~h}$ of mechanical stimulation and requires continued stimulation. Interestingly, the altered hypomethylation of Osteopontin that occurred with two weeks of biochemically induced differentiation was not dramatically different than that induced by $3 \mathrm{~h}$ of mechanical stimulation, suggesting that mechanical stimulation is a relatively strong regulator of Osteopontin expression.

In summary, we found that loading-induced oscillatory fluid flow, a candidate mechanical signal in the microenvironment of MSCs, has the potential to initiate osteogenic differentiation by not only upregulating Osteopontin gene expression, but by altering the methylated state of its promoter. Given that DNA methylation is preserved during replication, thus inherited by daughter cells, our results are a first demonstration of a molecular mechanism, whereby mechanical stimulation can produce durable alterations in gene expression during cell lineage commitment. With this observation of the overall effect of mechanical stimulation on epigenetic and genetic programs guiding osteogenic differentiation, future work can investigate other CPG sites within the regulatory regions of these and other genes as well as histone modifications of these regions.

\section{Conflict of interest statement}

We have no potential conflicts of interest.

\section{Acknowledgements}

This work was supported by an NSF Graduate Research Fellowship, Veterans Affairs Pre-Doctoral Associated Health Rehabilitation Research Fellowship, NIH Grant AR45989 and New York State Department of Health Stem Cell Program. We gratefully acknowledge advice and guidance provided by Dr. Helen M. Blau.

\section{References}

Antequera, F., 2003. Structure, function and evolution of $\mathrm{CpG}$ island promoters. Cell and Molecular Life Sciences 60, 1647-1658.

Ballestar, E., Wolffe, A.P., 2001. Methyl-CpG-binding proteins. Targeting specific gene repression. European Journal of Biochemistry/FEBS 268, 1-6.

Batra, N.N., Li, Y.J., Yellowley, C.E., You, L., Malone, A.M., et al., 2005. Effects of short-term recovery periods on fluid-induced signaling in osteoblastic cells. Journal of Biomechanics 38, 1909-1917.

Bird, A., 2002. DNA methylation patterns and epigenetic memory. Genes \& Development 16, 6-21.

Dehority, W., Halloran, B.P., Bikle, D.D., Curren, T., Kostenuik, P.J., et al., 1999. Bone and hormonal changes induced by skeletal unloading in the mature male rat. The American Journal of Physiology 276, E62-E69.

El-Osta, A., Wolffe, A.P., 2000. DNA methylation and histone deacetylation in the control of gene expression: basic biochemistry to human development and disease. Gene Expression 9, 63-75.

Estes, B.T., Gimble, J.M., Guilak, F., 2004. Mechanical signals as regulators of stem cell fate. Current Topics in Developmental Biology 60, 91-126.

Friedl, G., Schmidt, H., Rehak, I., Kostner, G., Schauenstein, K., Windhager, R., 2007. Undifferentiated human mesenchymal stem cells (hMSCs) are highly sensitive to mechanical strain: transcriptionally controlled early osteo-chondrogenic response in vitro. Osteoarthritis and Cartilage/OARS, Osteoarthritis Research Society $15,1293-1300$.

Fuks, F., Hurd, P.J., Wolf, D., Nan, X., Bird, A.P., Kouzarides, T., 2003. The methylCpG-binding protein MeCP2 links DNA methylation to histone methylation. The Journal of Biological Chemistry 278, 4035-4040.

Goldstein, S.A., 2006. Tissue engineering solutions for traumatic bone loss. The Journal of the American Academy of Orthopaedic Surgeons 14, S152-S156.

Jacobs, C.R., Yellowley, C.E., Davis, B.R., Zhou, Z., Cimbala, J.M., Donahue, H.J., 1998. Differential effect of steady versus oscillating flow on bone cells. Journal of Biomechanics 31, 969-976.

Kang, M.I., Kim, H.S., Jung, Y.C., Kim, Y.H., Hong, S.J., et al., 2007. Transitional CpG methylation between promoters and retroelements of tissue-specific genes during human mesenchymal cell differentiation. Journal of Cellular Biochemistry 102, 224-239.

Kim, C.H., You, L., Yellowley, C.E., Jacobs, C.R., 2006. Oscillatory fluid flow-induced shear stress decreases osteoclastogenesis through RANKL and OPG signaling. Bone 39, 1043-1047.

Kreke, M.R., Huckle, W.R., Goldstein, A.S., 2005. Fluid flow stimulates expression of osteopontin and bone sialoprotein by bone marrow stromal cells in a temporally dependent manner. Bone 36, 1047-1055.

Lachner, M., 2002. Epigenetics: SUPERMAN dresses up. Currrent Biology 12, R434-R436.

Lachner, M., Jenuwein, T., 2002. The many faces of histone lysine methylation. Current Opinion in Cell Biology 14, 286-298.

Lafage-Proust, M.H., Collet, P., Dubost, J.M., Laroche, N., Alexandre, C., Vico, L., 1998. Space-related bone mineral redistribution and lack of bone mass recovery after reambulation in young rats. The American Journal of Physiology 274, R324-R334

Li X., Zhao X. 2008. Epigenetic regulation of mammalian stem cells. Stem Cells and Development.

Li, Y.J., Batra, N.N., You, L., Meier, S.C., Coe, I.A., et al., 2004. Oscillatory fluid flow affects human marrow stromal cell proliferation and differentiation. Journal of Orthopaedic Research 22, 1283-1289.

Malone, A.M., Batra, N.N., Shivaram, G., Kwon, R.Y., You, L., et al., 2007. The role of actin cytoskeleton in oscillatory fluid flow-induced signaling in MC3T3-E1 osteoblasts. American Journal of Physiology 292, C1830-C1836.

McBeath, R., Pirone, D.M., Nelson, C.M., Bhadriraju, K., Chen, C.S., 2004. Cell shape, cytoskeletal tension, and RhoA regulate stem cell lineage commitment. Developmental Cell 6, 483-495.

Nagase, H., Ghosh, S., 2008. Epigenetics: differential DNA methylation in mammalian somatic tissues. The FEBS Journal 275, 1617-1623.

Noer, A., Sorensen, A.L., Boquest, A.C., Collas, P., 2006. Stable CpG hypomethylation of adipogenic promoters in freshly isolated, cultured, and differentiated mesenchymal stem cells from adipose tissue. Molecular Biology of the Cell 17, 3543-3556.

Reik, W., Dean, W., 2001. DNA methylation and mammalian epigenetics. Electrophoresis 22, 2838-2843.

Saunders, M.M., You, J., Trosko, J.E., Yamasaki, H., Li, Z., et al., 2001. Gap junctions and fluid flow response in MC3T3-E1 cells. American Journal of Physiology 281, C1917-C1925.

Saunders, M.M., You, J., Zhou, Z., Li, Z., Yellowley, C.E., et al., 2003. Fluid flow-induced prostaglandin E2 response of osteoblastic ROS 17/2.8 cells is gap junction-mediated and independent of cytosolic calcium. Bone 32, 350-356.

Triplett, J.W., O’Riley, R., Tekulve, K., Norvell, S.M., Pavalko, F.M., 2007. Mechanical loading by fluid shear stress enhances IGF-1 receptor signaling in osteoblasts in a PKCzeta-dependent manner. Molecular and Cellular Biomechanics 4, $13-25$.

Wolffe, A.P., Matzke, M.A., 1999. Epigenetics: regulation through repression. Science (New York, N.Y.) 286, 481-486.

Wronski, T.J., Morey-Holton, E.R., Doty, S.B., Maese, A.C., Walsh, C.C., 1987. Histomorphometric analysis of rat skeleton following spaceflight. The American Journal of Physiology 252, R252-R255. 
You, J., Reilly, G.C., Zhen, X., Yellowley, C.E., Chen, Q., et al., 2001. Osteopontin gene regulation by oscillatory fluid flow via intracellular calcium mobilization and activation of mitogen-activated protein kinase in MC3T3-E1 osteoblasts. The Journal of Biological Chemistry 276, 13365-13371.

You, J., Yellowley, C.E., Donahue, H.J., Zhang, Y., Chen, Q., Jacobs, C.R., 2000 Substrate deformation levels associated with routine physical activity are less stimulatory to bone cells relative to loading-induced oscillatory fluid flow. Journal of Biomechanical Engineering 122, 387-393.

Zhang, F., Pomerantz, J.H., Sen, G., Palermo, A.T., Blau, H.M., 2007. Active tissuespecific DNA demethylation conferred by somatic cell nuclei in stable heterokaryons. In: Proceedings of the National Academy of Sciences of the United States of America 104, 4395-4400. 